\section{Formal and Informal Sector Workers Care in Cameroon-Need for Equitable Protection Approach based on Rational Assessment of Risks and Exposures through Carpenter's Respiratory System Assessment}

\section{Abstract}

We explored respiratory symptoms in informal versus formal sector workers, in order to find out if there is rational reason for selective care towards the latters.

Methodology: This was a transversal analytic study comparing spirometry parameters of 35 carpenters from informal sector activity to 35 controls from official sector, all males, matched for body surface area, in Douala town in Cameroon, from March to May 2015. We performed spirometries and clinical examinations. We analysed data with spss V.22.

Results: The carpenters and the controls showed respectively that : average age was 35 vs 34 years; average years spent in function : 13 vs 9 years ; systolic blood pressure : 120 vs $115 \mathrm{mmHg}(p<0.05)$; diastolic blood pressure : 79 vs 96 $\mathrm{mmHg}$; on spirometry, forced vital capacity : 97 vs 92 ; forced expiratory volume per second : 101 vs 96 ; Tiffeneau index : 108 vs 105 ; and peak expiratory flow : 91 vs 87 . A negative correlation was found in carpenters between lenght of stay in function in years and peak expiratory flow $(R=-0.34 ; p<0.05)$.

Conclusion : The spirometry parameters are more altered in the carpenters of informal sector, compared to controls of formal sector. There are no abnormalities exclusively present in formal sector workers that could justify their selective care. This study highlights the need for a real attention to all workers in terms of preventing their health problems by authorities

Keywords: Occupational, Wood dust, Workforce, Lung

\section{Francis NDE ${ }^{1}$, Armel Djomo ${ }^{2}$, Jules Nebo ${ }^{2}$ and Christophe De Brouwer ${ }^{3}$}

\section{Environmental Health \& Health at Work Research Center, School of Public Health, Free University of Brussels, Belgium \\ 2 Foundation Heart \& Life, University of Douala, Cameroon \\ 3 Environmental Health \& Health at Work Research Center, School of Public Health, Free University of Brussels, Belgium}

\section{Corresponding author: Francis NDE}

\section{Đndedjie@ulb.ac.be}

Environmental Health \& Health at Work Research Center, School of Public Health, Free University of Brussels, Belgium.

Tel: +32 25554032

Citation: Francis NDE, Djomo A, Nebo J, et al. Formal and Informal Sector Workers Care in Cameroon-Need for Equitable Protection Approach based on Rational Assessment of Risks and Exposures through Carpenter's Respiratory System Assessment. Insights Allergy Asthma Bronchitis. 2015, 1:1.

Received: August 24, 2015; Accepted: October 02, 2015; Published: October 05, 2015

\section{Introduction}

According to scientific approximations, respiratory diseases will probably become the third major cause of death worldwide in 2020, from a sixth position in 1990 [1]. Several studies have been focused on respiratory cancers caused by wood in different parts of the world [2,3]. There is sufficient evidence for the carcinogenicity of wood dust on nasal cavity, paranasal sinuses and nasopharynx in humans. Despite the expanded use of wood in several factories and informal sector activities, with potential consequences on wellbeing and on work productivity, only a few scientific researchers are interested on non-cancer effects of this exposition on respiratory tract, particularly in sub-Saharan Africa. Wood dust is recognized as an occupational hazard by scientists [4] and European Union has made it an issue for workers protection [5] because wood dust may cause cancers [6], professional asthma [7] and other allergic conditions which all diminishes the quality of life [8]. Therefore this phenomenon is seriously taken into consideration in developed countries. On 
the other hand workers' (mainly carpenters) protection seems not been prioritized in developing countries, particularly in subSaharan Africa. The carpentry is a largely expanded profession in Cameroonian population. Worker's care in the country, in terms of law is mainly focused on formal sector workforces, meanwhile informal sector workers as well, are exposed to possible risks during their activity. Few studies were interested in informal sector workers, but have focused on other professions such as bakers $[9,10]$. We feel a simple and practical tool for assessing respiratory effect of dust on workers' health is the spirometer, previously used in similar contexts [11,12]. There is no study in the literature regarding this issue in Cameroon. Therefore, in order to find out if there is a rational reason for a selective care for formal sector workers, excluding the other category, we explored respiratory symptoms and abnormalities found on spirometry studies among the two groups.

\section{Methodology}

This was a transversal analytic study conducted from March to May 2015, comparing spirometry parameters of 35 carpenters from informal sector activity with respect to 35 controls from official sector in Douala town in Cameroon. All subjects were males, matched for body surface area. The town was divided into 6 districts. In each of them, 5 to 6 subjects were randomly selected in the carpenters group. For each carpenter, a matched counterpart control from another activity in the formal sector was randomly selected. All selection was made after explaining the study to the subject, and if the person was willing, and informed consent form was signed as requested by the Cameroon Association of General Practitioners. The informal sector subject was weighed and his height was measured in our research center, and when we had the same BSA or close to a formal sector carpenter's BSA with a maximum difference of 0.01 , we matched the two cases. We proceeded the same way till we matched all the carpenters to controls. After matching process, information on job histories and length of stay in the job was obtained through an interview. A Clinical assessment was further performed in the research center, where a spirometry was also carried out at rest, then ten minutes after bronchodilation using salbutamol spray. The same trained investigator conducted all the assessments using the same spirometer. We used electronic portable spirobank
II MIR (commonly manual portable spirometer used by the occupational Physicians in Cameroon, in order to be close to local practice in occupational medicine in formal sector). We applied recommended method, provided by the manufacturer. We recorded the following parameters: forced vital capacity (FVC), forced expiratory volume in one second (FEV1), forced expiratory flow 25-75 (FEF 25-75), peak expiratory flow (PEF), Tiffeneau index (FEV1/FVC x 100). We calculated body surface area (BSA) using Dubois formula. Data were collected and encoded in a SPSS V.22 and the same served for the analysis. We compared the values of spirometry between the two groups. We calculated the airway dilation based on the fact that, at rest they could be considered as being exposed to some degree of airways obstruction. We then calculated such a reduction average difference in each group and then compared the average between the two groups.

\section{Results}

The two groups had similar BSA and their respiratory parameters could be compared, as they may vary depending on the subject's BSA. There was no significant difference of the mean values of age, weight and height and BSA, between the two groups (Table 1).

Spirometry parameters between carpenters and controls respectively are as follow: Forced Vital Capacity (FVC): 92 vs. 91(Table 2); Forced Expiratory Volume per second (FEVs): 101 vs. 96 (Table 2); Tiffeneau index: 108 vs. 101 (Table 2); Forced Expiratory Flow (FEF) 25-75: 99 vs. 89 and Peak Expiratory Flow (PEF) 91 vs 87 (Table 2). For all these parameters, only the difference in FEF25-75 was close to be significant threshold.

The differences of mean values between measurement on rest and post bronchodilation spirometry data for the two groups of workers were not statistically significant (Table 3).

The average years spent in function was 13 years for the carpenters and 9 years for the controls (Table 4). The carpenters had significant higher systolic blood pressure mean value than the controls: 120 vs $115 \mathrm{mmHg}(p<0.05)$ while diastolic blood pressures mean values were not significantly different between the carpenters and the controls: resp. 79 vs $76 \mathrm{mmHg}$ (Table 4).

\section{Discussion}

Work place safety is a lacking issue in developing and underdeveloped

Table 1 Comparing anthropologic and clinical data of the two groups of workers.

\begin{tabular}{|c|c|c|c|c|c|}
\hline Variable & Controls & Carpenters & difference & $95 \% \mathrm{Cl}$ & p-value \\
\hline Weight (kg) & 75.11 & 76.14 & 1.02 & -2.5 to 4.5 & 0.566 \\
\hline Height (cm) & 170.86 & 171.91 & 1.06 & -1.67 to 3.78 & 0.436 \\
\hline BMI & 25.67 & 25.77 & 0.1 & -1.65 to 1.76 & 0.905 \\
\hline Age (years) & 35.02 & 34.40 & 0.63 & -5.03 to 3.78 & 0.774 \\
\hline Hear Rate (per min) & 68.7 & 70.8 & 2.11 & -7.40 to 3.17 & 0.422 \\
\hline $\mathrm{SBP}(\mathrm{mmHg})$ & 120.40 & 114.71 & 5.69 & -10.02 to -1.35 & $0.012 *$ \\
\hline DBP (mmHg) & 79.00 & 76.29 & 2.71 & -6.23 to 0.80 & 0.126 \\
\hline
\end{tabular}

* Statistically significant

Comparing means was performed using t-student test for paired samples in SPSS version 22.0.

BMI: Body Mass Index.

SBP: Systolic Blood Pressure.

DBP: Diastolic Blood Pressure 
Table 2 Comparing rest spirometry data of the two groups of workers.

\begin{tabular}{|c|c|c|c|c|c|}
\hline Variable & Controls & Carpenters & difference & $95 \% \mathrm{Cl}$ & p-value \\
\hline FVC & 96.91 & 92.23 & 4.69 & -12.47 to 3.10 & 0.230 \\
\hline FEVs & 101.23 & 96.00 & 5.23 & -12.85 to 2.39 & 0.172 \\
\hline Tiffeneau index & 107.97 & 105.17 & 2.8 & -8.02 to 2.42 & 0.284 \\
\hline FEF $25-75$ & 99.31 & 89.54 & 9.77 & -19.74 to 0.20 & 0.055 \\
\hline PEF & 90.51 & 86.88 & 3.63 & -12.34 to 5.09 & 0.404 \\
\hline
\end{tabular}

Comparing means was performed using t-student test for paired samples in SPSS version 22.0.

FVC: Forced vital capacity.

FEVs: Forced Expiratory Volume per Second.

FEF: Forced Expiratory Flow.

PEF: Peak Expiratory Flow.

Table 3 Comparing means differences between rest measurement and post bronchodilation spirometry data of the two groups of workers.

\begin{tabular}{|c|c|c|c|c|c|}
\hline Variable & Controls & Carpenters & difference & 95\% Cl & p-value \\
\hline FVC & 0.013 & 0.15 & 0.002 & -0.09 to 0.09 & 0.959 \\
\hline FEVs & 0.013 & 0.002 & -0.10 & -0.103 to 0.081 & 0.817 \\
\hline Tiffeneau index & 0.010 & 0.005 & -0.004 & -0.041 to 0.032 & 0.818 \\
\hline FEF 25-75 & 0.027 & 0.005 & -0.217 & -0.115 to 0.071 & 0.639 \\
\hline PEF & -0.046 & -0.057 & -0.011 & -0.142 to 0.119 & 0.860 \\
\hline
\end{tabular}

Comparing means was performed using t-student test for paired samples in SPSS version 22.0.

FVC: Forced vital capacity.

FEVs: Forced Expiratory Volume per Second.

FEF: Forced Expiratory Flow.

PEF: Peak Expiratory Flow.

Table 4 Comparing correlation between age or duration of stay in the job on one hand, and spirometry or clinical parameters on the other hand, in the two groups.

\begin{tabular}{|c|c|c|c|c|c|c|}
\hline \multirow[t]{2}{*}{ Variable } & \multicolumn{3}{|c|}{ Carpenters } & \multicolumn{3}{|c|}{ Controls } \\
\hline & $\mathrm{R}$ & $R^{2}$ & Sig & $\mathrm{R}$ & $R^{2}$ & Sig \\
\hline $\begin{array}{l}\text { SBP: } \\
\text { Age } \\
\text { Duration in job }\end{array}$ & $\begin{array}{l}-0.299 \\
-0.068\end{array}$ & $\begin{array}{r}0.089401 \\
0.004624\end{array}$ & $\begin{array}{l}0.081 \\
0.700\end{array}$ & $\begin{array}{l}0.213 \\
0.177\end{array}$ & $\begin{array}{l}0.045369 \\
0.031329\end{array}$ & $\begin{array}{l}0.219 \\
0.308\end{array}$ \\
\hline $\begin{array}{l}\text { DBP: } \\
\text { Age } \\
\text { Duration in job }\end{array}$ & $\begin{array}{l}-0.051 \\
0.005\end{array}$ & $\begin{array}{l}0.002601 \\
0.000025\end{array}$ & $\begin{array}{l}0.771 \\
0.979\end{array}$ & $\begin{array}{l}0.367 \\
0.369\end{array}$ & $\begin{array}{l}0.134689 \\
0.136161\end{array}$ & $\begin{array}{l}0.030 \\
0.029 *\end{array}$ \\
\hline $\begin{array}{l}\text { FEF25-75 post bronchial dilation } \\
\text { Age } \\
\text { Duration in job }\end{array}$ & $\begin{array}{l}-0.355 \\
-0.296\end{array}$ & $\begin{array}{l}0.126025 \\
0.087616\end{array}$ & $\begin{array}{l}0.037 \\
0.084\end{array}$ & $\begin{array}{l}-0.388 \\
-0.328\end{array}$ & $\begin{array}{l}0.1500544 \\
0.1075840\end{array}$ & $\begin{array}{l}0.074 \\
0.054\end{array}$ \\
\hline $\begin{array}{l}\text { PEF post bronchial dilation } \\
\text { Age } \\
\text { Duration in job }\end{array}$ & $\begin{array}{l}-0.347 \\
-0.324\end{array}$ & $\begin{array}{l}0.120409 \\
0.104976\end{array}$ & $\begin{array}{l}0.041 * \\
0.057\end{array}$ & $\begin{array}{l}-0.036 \\
-0.337\end{array}$ & $\begin{array}{l}0.001296 \\
0.113569\end{array}$ & $\begin{array}{l}0.838 \\
0.048^{*}\end{array}$ \\
\hline
\end{tabular}

countries. We compared two groups: Informal- who regularly exposed to wood dust with formal. Our two groups studied were well-matched for BSA. This was a voluntary choice to make our two groups comparable. Although some cases of variation of blood pressure related to profession could be found in a European study in 2011 by Schumann and al. [13] However in our study, blood pressure measurement showed a higher average at rest only for systolic values, but all values remained on normal ranges [14]. The diastolic values were similar in the two groups. In our study we could not find a relation between blood pressure and type of work as per Tsutsumi et al. [15]. We can't rule out healthy worker effect in our case. Indeed such activity requires repetitive movements and ergonomic constraints [16], wick workers will likely stay home.

Although carpenters exposed to wood dust may be expected to present with more altered spirometry due to different components found in wood dust [17], the difference in forced vital capacity was not significant between the two groups despite a slight higher value. The same observation was made about Tiffeneau index and the peak expiratory flow between the two groups, carpenters showing lower values. Both groups are exposed to environmental factors as they are outdoor workers. In all the two groups, values were within normal ranges and healthy workers effect could neither be ruled out. Indeed none of them used personal protective equipment. Forced expiratory volume per second showed slightly higher value in informal sector workers (though not significantly different) (Table 2).

In a study comparing the same parameters in pump workers versus unexposed healthy workers, Solanki et al. [18] found a significant difference. A possible reason for lack of difference between 
the carpenters and the controls in our research is that our two groups were all exposed to quiet similar environmental factors, meanwhile in the previously mentioned study; one category was healthy and not exposed at all to the factor incriminated. In fact, study reveals that other factors such as environmental polluted air, mainly components possibly from combustion-related sources may play an important role in upper airways alteration.

In our carpenters, we found a significant negative correlation between diastolic blood pressure and length of stay in the job. Long duration in the same job has been showed for some categories of informal sector workers to have an impact on their health in previous study. The longer carpenters were exposed in time to their job; the lower could be the blood pressure at rest [19]. Indeed, as previously showed, this situation could be attributable to a higher physical work load, lowering their blood pressure over time [19]. This argument pleads for a better care for informal sector workers. In the same group, we could find a negative correlation between lifetime in the profession and peak expiratory flow values after bronchial dilation. In the scientific literature $[7,20]$, length of exposure to wood dust is a known factor that impacts peak expiratory flow in workers. In their study Mohan et al. [21] found peak expiratory flow to be impared in carpenters. Mroczek et al. [8] found serious asthma related alterations to such similar exposures. PEF variation has been shown to occur over time, in workers exposed to substances causing respiratory hazards [22]. In our study, this effect is only observed in carpenters and not in controls, making informal workers in carpentries one of the vulnerable categories with a real need of care, to be raised to the same protection level with other workers.

\section{Conclusion}

Despite some limitations, as probably all studies, it was worth exploring wood dust exposure in Cameroon, a developing country of sub-Saharan Africa, to show the interest of caring about informal sector workers, who highly contribute to the economic development of this state. This study clearly showed that there is no difference in the abnormalities found between the two categories of workers that may justify a selective care for formal sector workers. Rather, some parameters are more deteriorated in the carpenter group. This study also highlights the need for a real attention by the health authorities in terms of general health workers prevention. Therefore, it is essential to apply international rules in health safety for all the workers as recommended by the International Labor Organization (ILO). In other terms, there is no rational reason to address only formal sector workers, and exclude others. Our study helps in a step forward towards workers protection, in a context whereby prevention culture is nearly absent or very selective.

\section{Acknowledgments}

To all participants who agreed for the study as well as all participant centers.

Researcher teams working in those centers.

Free University of Brussels Occupational medicine and environmental health departments.

Fondation Cœur-vie in Douala Cameroon.

Cameroon Society of General Practitioners.

Cameroon Society of Security and Health at Work. 


\section{References}

1 Raherison C (2005) Epidemiologie de la bronchopneumopathie chronique obstructive. Presse Med 38: 400-5.

2 Serrier H, Sultan-Taieb H, Luce D, Bejean S (2014) Estimating the social cost of respiratory cancer cases attributable to occupational exposures in France. Eur J Health Econ 15: 661-73.

3 Smailyte G (2012) Cancer incidence among workers exposed to softwood dust in Lithuania. Occup Environ Med 69: 449-51.

4 Vial-Dupuy A (2015) Allergies respiratoires chez les professionnels du bois. Allergie-pneumologie professionnelle. Références en santé au travail.

5 Baran S, Teul I (2007) Wood dust: an occupational hazard which increases the risk of respiratory disease.J PhysiolPharmacol 5: 43-50.

6 Alonso-Sardón M, Chamorro AJ, Hernández-García I, Iglesias-de-Sena $\mathrm{H}$, Martín-Rodero H, et al. (2015) Association between Occupational Exposure to Wood Dust and Cancer: A Systematic Review and MetaAnalysis. PLoSOne 10: e0133024.

7 Hannu T, Lindström I, Palmroos P, Kuuliala O, Sauni R (2013) Prediction of obeche wood-induced asthma by specific skin prick testing. OccupMed (Lond) 63: 429-31.

8 Mroczek B, Kurpas D, Urban M, Sitko Z, Grodzki T (2015) The Influence of Asthma Exacerbations on Health-Related Quality of Life. Adv ExpMedBiol.

9 Mbatchou Ngahane BH, NdeF, NgomoE, AfaneZe E (2015)Sensitization to workplace respiratory allergens among bakery workers in Douala, Cameroon: a cross-sectional study. AllergyAsthmaClinImmunol 10: 11(1)-13.

10 Mbatchou Ngahane BH, Afane Ze E, Nde F, Ngomo E, MapoureNjankouo $Y 5$, et al.Prevalence and risk factors for allergic rhinitis in bakers in Douala, Cameroon. BMJ Open 1: 4(8).

11 Mwaiselage J, Moen B, Bråtveit M (2006) Acute respiratory health effects among cement factory workers in Tanzania: an evaluation of a simple health surveillance tool. Int Arch Occup Environ Health 79: 49-56.
12 Zeleke ZK1, Moen BE, Bråtveit M (2010) Cement dust exposure and acute lung function: a cross shift study.BMC Pulm Med 10: 19.

13 Schumann B1, Seidler A, Kluttig A, Werdan K, Haerting J, et al. (2011) Association of occupation with prevalent hypertension in an elderly East German population: an exploratory cross-sectional analysis. Int Arch Occup Environ Health. 84: 361-9.

14 Mbatchou Ngahane BH, Nganda MM, Dzudie A, Luma H, Kamdem F, et al. (2015) Prevalence and determinants of excessive daytime sleepiness in hypertensive patients: a cross-sectional study in Douala, Cameroon. BMJ Open 5: e008339.

15 Tsutsumi A, Kayaba K, Tsutsumi K, Igarashi M (2001) Jichi Medical School Cohort Study Group. Association between job strain and prevalence of hypertension: a cross sectional analysis in a Japanese working population with a wide range of occupations: the Jichi Medical School cohort study. Occup Environ Med 58: 367-73.

16 Parida R1, Ray PK (2012) Study and analysis of occupational risk factors for ergonomic design of construction work systems. Work 1: 3788-94.

17 Laraqui Hossini CH, LaraquiHossini O, Rahhali AE, Verger C, Tripodi D, et al. (2001) Respiratory risk in carpenters and cabinet makers. Rev Mal Respir 18: 615-22.

18 Solanki RB, Bhise AR, Dangi BM (2015) A study on spirometry in petrol pump workers of Ahmedabad, India. Lung Indi 32: 347-52.

19 Nde F, Nebo J, Ngatchou W, Tchatchoua C, Sone AM, et al. (2014) Impact of heavy load activity on cardiovascular system: echocardiographic assessment of informal construction workers heart in Cameroon.Pan Afr Med J 31: 17-79.

20 Meo SA (2014) Effects of duration of exposure to wood dust on peak expiratory flow rate among workers in small scale woodindustries. Int J Occup Med Environ Health 17: 451-5.

21 Mohan M1, Aprajita, Panwar NK (2013) Effect of wood dust on respiratory health status of carpenters. J ClinDiagn Res 7: 1589-91.

22 Lawin H, Ayelo P, Hinson V, Kagima J, Fayomi B (2015) Change in peak expiratory flow over time among workers exposed to polyvinyl chloride dust.Int J TubercLung Dis 19: 488-91. 